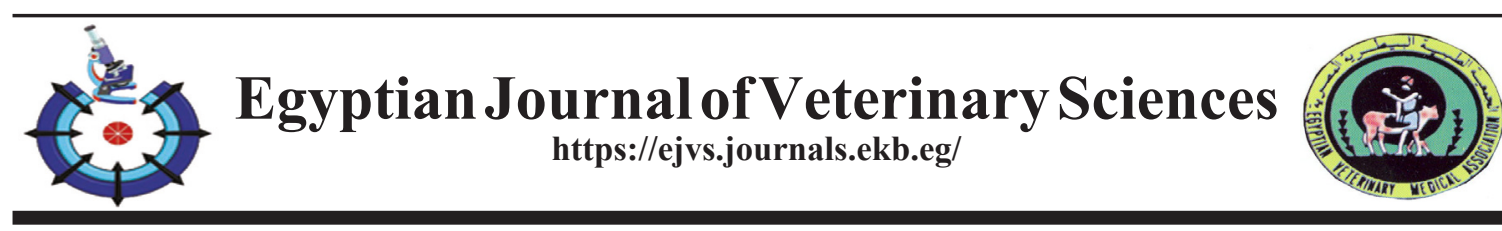

\title{
Clinico-hematobiochemical and Pathological Study of Acute Nutritional Muscular Dystrophy of Adult Buffalo Calves at Basrah, Iraq
}

\author{
Kamal M. Alsaad, Mohanad H. Lafta and Ali Jarad \\ College of Veterinary Medicine, Department of Internal and Preventive Medicine, \\ University of Basrah, Iraq.
}

\begin{abstract}
YLINICAL, biochemical and pathological studies of adult buffalo calves at Basrah, Iraq were conducted on 64 suspected calves with muscular dystrophy, and other 10 clinically healthy animals was served as controls. Suspected calves have a history of recent turnout of exercise and reared in lush green grazing areas. Diseased calves showed different clinical signs, include sudden onset of dullness, Loss of appetite, lateral recumbence and difficulty to rise , panting with mouth breathing, Irregular heartbeats on auscultation, and acute death within $24 \mathrm{hrs}$. However, Macrocytic normochromic anemia was detected by the hematological examinations. A significant hypo -thrombocytopenia and a significant difference of clotting factor indices were also indicated. Moreover, the results of the biochemical changes showed a statistically significant decrease $(\mathrm{P}<0.05)$ in $\alpha$-tocopherol, Glutathione peroxidase, Whereas, a significant increase $(\mathrm{P}<0.05)$ in the values of Aspartate aminotrasferase (AST), Creatine kinase $(\mathrm{CK})$ and Troponin I in the diseased animals than controls has been indicated. The cross pathological results of carcasses indicated enlargement of the heart which appears spherical-like in shape. There were small white patches on the epicardial surface. However, petechial hemorrhages on the epicardial surface were also indicated. The histopathological findings revealed mild to severe diffuse vacuolar changes (degeneration) in the myocardial fibers, a thrombotic mass revealed to inflammatory cell infiltration, and areas of severe fibrosis accompanied by inflammatory cell infiltration which revealed to interstitial diffuse fibro-myocarditis was also detected. It was concluded that acute dystrophy of cardiac muscles has a harmful effect on diseased calves mostly terminated with sudden death.
\end{abstract}

Keywords: Vitamin. E and Selenium deficiency, Buffalo calves, Iraq.

\section{Introduction}

When review the history of vitamin $\mathrm{E}$, it became clear that Evans and Bishop in 1922, were the first who discovered it and infer the vitamin functions as an (anti-sterility factor $\mathrm{X}$ ) which is important for reproduction [1].

Afterwards, vitamin E was distinguished clearly and to be known as a strong lipid and soluble antioxidant via different scientific studies. The antioxidant functions of the Vitamin . E has been reported where, it can sweep the reactive $\mathrm{O}_{2}$ elements in most cell membranes of a live body[2].
Vitamin E, which contains two mixtures of the tocotrienols and the tocopherols, is obtained from different food plants, and some oils that are edible such as, oat, bran, rice, coconut, barley, wheat, annatto, and the palm [3].

Muscular dystrophy, which related to the deficiency of vitamin $\mathrm{E}$ and /or selenium was classified according to the disorders indicated in different animals mostly the young, and rapidly growing animals, as well as newly adult animals [4]. On the other hand, it was proved that the muscular dystrophy disease in cattle and buffalo appears in 
young suckling calves, cattle more than one-yearold at the beginning of the grazing period, and in late pregnancy and post-parturient [5]. In addition vitamin $\mathrm{E}$ and selenium deficiency, increase consumption of unsaturated fatty acids which will increase the concentration of hydro-peroxides in the organism organs. Moreover, a muscular strain beside the bad climate may be encourage the clinical development of muscular dystrophy disease in animals [6].

The aims of the present work is to clarify the clinical hematobichemical and pathological effects of acute nutritional muscular dystrophy which was suspected in clinical cases of adult buffalo calves at Basrah, Iraq.

\section{Materials and Methods}

\section{Ethical considerations}

The moral and ethical values required and universally agreed upon were used in dealing with study animals in this research.

This study was conducted at Basrah, Iraq during 2020 on 64 adult buffalo calves, 8-10 months old(Males and Females) with a history of recent turnout of exercise and reared in lush green grazing areas, with dry feeding at night time, The calves showed signs of sudden onset of dullness, panting with mouth breathing, and acute death within 24hrs. Ten (10) clinically healthy adult buffalo calves served as controls. All calves were subjected to complete clinical and laboratory examinations.

\section{Hematological analysis}

Ten $\mathrm{ml}(10 \mathrm{ml})$ of blood was drained from the jugular vein, divided into two parts, First part was $5 \mathrm{ml}$ on Ethylenediaminetetraacetic acid (EDTA) blood part was used to determine Total red blood cells (RBC), Hemoglobin concentration ( $\mathrm{Hb}$ ) concentration, packed cell volume (PCV), Total platelet count (TPC) and total leukocyte count (TLC) on the full digital cell counter from the USA.

Clotting factor indices were performed according to manufacture instructions from (Biolabo / France) using plasma and including an evaluation of the platelet distribution width, mean platelet volume, prothrombin time, activated partial prothrombin time, and fibrinogen time. Moreover, The clotting time was evaluated according to Dayyal, 2016 [7].

Giemsa stained blood smears are used according to Weiss, and Wardrop (2010) [8]. to calculate the differential leukocyte count (DLC). Moreover, it also used to identify the blood parasitic infestation if found.

\section{Biochemical analysis}

It was included for the evaluation of: Vit E, ( $\alpha$-tocopherol) (A spectrophotometer method, using commercial Colorimetric Assay Kit from Elabscience Biotechnology, USA) .Evaluation of Serum Glutathione peroxides assay (sandwich enzyme-linked immune-sorbent assay) According to manufacturerss instructions from the Alshkairate establishment for medical supply, Jordon. Evaluation of Troponin I assay ELISA kits from diagnostic automation / Cortez Dianostics, INC, USA. And evaluation of: Creatine kinase(CK) and Aspartate aminotrasferase (AST), (A spectrophotometer method, using commercial kits from Roche Diagnostics, Indianapolis, GMBH, Germany).

\section{Statistical analysis}

The statistical analysis was done using SPSS the student $t$-test [9].

\section{Results}

Diseased adult buffalo calve breeds showed different clinical signs include sudden onset of dullness(93.7\%), loss of appetite $(84.3 \%)$, lateral recumbence and difficulty to rise $(79.6 \%)$, panting with mouth breathing $(78.12 \%)$, Irregular heartbeats on auscultation(68.7\%), and acute death within $24 \mathrm{hrs}(18.75 \%)$ (Table 1).

Results of clinical examinations of diseased adult buffalo calves show also a significant increase $(\mathrm{P}<0.05)$ in heart and respiratory rate of diseased animals compared with controls (Table 2).

Results of hematological analysis of diseased adult buffalo calves indicated macrocytic normochromic anemia due to the significant $(\mathrm{P}<0.05)$ lower of the total red blood cells $(\mathrm{RBC})$ count, the hemoglobin concentration $(\mathrm{Hb})$, and the packed cell volume (PCV) values of the diseased calves than the control calves (Table 3 )

On the other hand, a significant $(\mathrm{P}<0.05)$ hypo -thrombocytopenia and hypofibrinogenemia as well as, a statistically significant increase $(\mathrm{P}<0.05)$ of percentage amounts of the platelet distribution width, the mean platelet volume, the clotting time, the prothrombin time and the activated partial thromboplastin time, was also indicated in diseased adults buffalo calves than in the control calves (Table 4) 
TABLE 1. Clinical signs of diseased adult buffalo calves.

\begin{tabular}{lcc}
\hline Clinical signs & Number of diseased calves $\mathbf{n}=\mathbf{6 4}$ & $\mathbf{\%}$ \\
\hline Sudden onset of dullness & 60 & 93.7 \\
Loss of appetite & 54 & 84.3 \\
Lateral recumbence and difficulty to rise & 51 & 79.6 \\
Panting with mouth breathing & 50 & 78.12 \\
Irregular heartbeats on auscultation & 44 & 68.7 \\
Acute death within 24-48 hrs & 12 & 18.75 \\
\hline
\end{tabular}

TABLE 2. Clinical examinations of diseased adult buffalo calves and controls.

\begin{tabular}{|c|c|c|}
\hline $\begin{array}{l}\text { Clinical examination Param- } \\
\text { eters }\end{array}$ & Controls Ten healthy calves $(n=10)$ & Diseased calves $(n=64)$ \\
\hline Body temperature ${ }^{\circ} \mathrm{C}$ & $38.6 \pm 0.34$ & $38.8 \pm 0.87$ \\
\hline Heart rate/min & $92 \pm 3.76$ & $161 \pm 5.38^{*}$ \\
\hline Respiratory rate/min & $27 \pm 3.56$ & $63 \pm 6.78^{*}$ \\
\hline
\end{tabular}

*P $<0.05$ is the statistical value between diseased adult buffalo calves and the controls .

TABLE 3. Hematological parameters of diseased adult buffalo calves and controls.

\begin{tabular}{|c|c|c|}
\hline Hematological parameters & Controls $(n=10)$ & Diseased calves $(n=64)$ \\
\hline $\mathrm{RBC} \times 10^{6}$ & $7.52 \pm 1.43$ & $5.33 \pm 1.21^{*}$ \\
\hline $\mathrm{Hb} \mathrm{mg} / \mathrm{dl}$ & $12.22 \pm 1.53$ & $9.64 \pm 2.43^{*}$ \\
\hline PCV \% & $34.64 \pm 2.11$ & $26.52 \pm 4.34^{*}$ \\
\hline $\mathrm{MCV}$ fl & $46.06 \pm 4.66$ & $49.75 \pm 5.72 *$ \\
\hline $\mathrm{MCHC} \mathrm{g} / \mathrm{dl}$ & $35.26 \pm 3.53$ & $36.34 \pm 4.61$ \\
\hline TLC $\times 10^{3}$ & $12.32 \pm 1.43$ & $12.44 \pm 1.56$ \\
\hline Neutrophils /absolute & $5833 \pm 404.18$ & $5845 \pm 281.11$ \\
\hline Lymphocytes/absolute & $5201 \pm 342.88$ & $5231 \pm 312.21$ \\
\hline Monocytes/absolute & $566 \pm 289$ & $576.45 \pm 211$ \\
\hline Eosinophils /absolute & $384 \pm 21$ & $392 \pm 12$ \\
\hline Basophils /absolute & $79 \pm 51$ & $80 \pm 62$ \\
\hline
\end{tabular}

$* \mathrm{P}<0.05$ is the statistical value between diseased adult buffalo calves and the controls .

TABLE 4. Clotting factor indices of diseased adult buffalo calves and controls.

\begin{tabular}{lcc}
\hline \multicolumn{1}{c}{ Clotting factor indices parameter } & $\begin{array}{c}\text { Controls Ten } \\
\text { healthy calves } \\
(\mathbf{n = 1 0 )}\end{array}$ & $\begin{array}{c}\text { Diseased calves } \\
\text { (n=64) }\end{array}$ \\
\hline The total platelet count / g/L & $488.67 \pm 23.77$ & $288.45 \pm 34.53^{*}$ \\
The platelet distribution width \% & $17.43 \pm 2.45$ & $25.57 \pm 4.76^{*}$ \\
The mean platelet volume /fL & $8.67 \pm 1.67$ & $16.32 \pm 4.56^{*}$ \\
The clotting time/min. & $3.54 \pm 1.21$ & $4.76 \pm 1.92^{*}$ \\
The prothrombin time/sec. & $15.43 \pm 1.76$ & $19.32 \pm 2.78^{*}$ \\
The activated partial thromboplastin time/sec. & $53.81 \pm 2.72$ & $67.21 \pm 3.56^{*}$ \\
Fibrinogen time / sec & $22.74 \pm 3.67$ & $12.17 \pm 6.81^{*}$ \\
\hline$* \mathrm{P}<0.05$ is the statisti
\end{tabular}

*P $<0.05$ is the statistical value between diseased adult calves and the controls. 
Moreover, the results of the biochemical changes between the diseased adult buffalo calves and the control animals show a statistically significant decrease $(\mathrm{P}<0.05)$ in $\alpha$-tocopherol, and Glutathione peroxidase, whereas, a significant increase $(\mathrm{P}<0.05)$ in the values of AST, CK and Troponin I in the diseased animals than controls has been indicated (Table 5).

The cross pathological results of carcasses indicate enlargement of the heart which appears spherical-like in shape. However, the right ventricle was similar in size to the left. There was a small white patch on the epicardial surface(whitecolored lesions of degeneration, which appears more evident, particularly under the endocardium) (Fig.1). A petechial hemorrhage on the epicardial surface was also indicated (Fig. 2). Moreover, the lungs are congested, edematous, and dark red with presence of white froth in the trachea. A proteinrich edematous fluid was present within alveolar lumina and interlobular septa. Furthermore, no line of demarcation refers to pneumonia and the intestinal contents showed pasty with yellow materials.

The histopathological findings revealed, mild to severe diffuse vacuolar changes (degeneration) in the myocardial fibers in addition to a thrombotic mass revealed to inflammatory cell infiltration, Moreover, areas of severe fibrosis accompanied by inflammatory cell infiltration revealed to interstitial diffuse fibro-myocarditis was also indicated. On the other hand,

The lungs showed changes consistent with heart failure, Moreover, The alveoli were also contained some fibrin casts and mild infiltrate of macrophages and a high number of neutrophils. Furthermore, Focal hemorrhages were also present (Fig. 3,4 and 5).

TABLE 5. Biochemical analysis of diseased adult buffalo calves and controls.

\begin{tabular}{lcc}
\hline \multicolumn{1}{c}{ Biochemical parameters } & $\begin{array}{c}\text { Controls Ten healthy } \\
\text { calves }(\mathbf{n}=\mathbf{1 0})\end{array}$ & Diseased calves( $\mathbf{n = 6 4 )}$ \\
\hline$\alpha$-tocopherol mg/L & $19 \pm 1.22$ & $7.57 \pm 0.24 *$ \\
Glutathione Peroxidase $\mathrm{mU} / \mathrm{mg} \mathrm{Hb}$ & $30 \pm 2.45$ & $16 \pm 1.67^{*}$ \\
$\mathrm{AST} \quad \mathrm{IU} / \mathrm{L}$ & $87 \pm 3.54$ & $624 \pm 5.78^{*}$ \\
$\mathrm{CK} \quad \mathrm{IU} / \mathrm{L}$ & $28 \pm 1.42$ & $2341 \pm 4.59^{*}$ \\
Troponin I $\mathrm{ng} / \mathrm{ml}$ & $0.23 \pm 0.04$ & $25 \pm 2.67^{*}$ \\
\hline
\end{tabular}

$* \mathrm{P}<0.05$ is the statistical value between diseased adult buffalo calves and the controls .
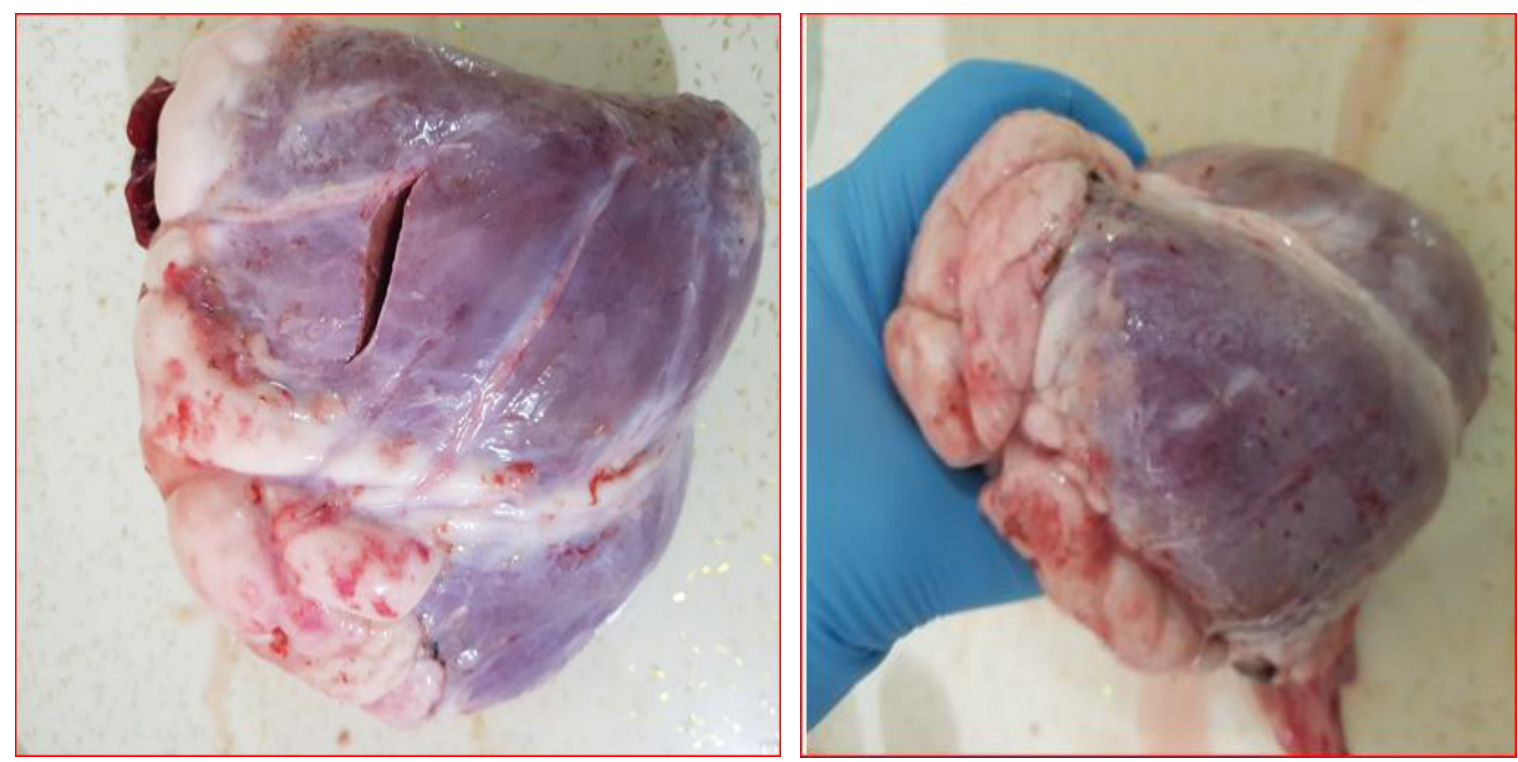

Fig. 1\&2. Spherical shape heart with a white patch (black arrows) and petechial hemorrhages (white arrow).

Egypt. J. Vet. Sci. Vol. 52, No. 3 (2021) 


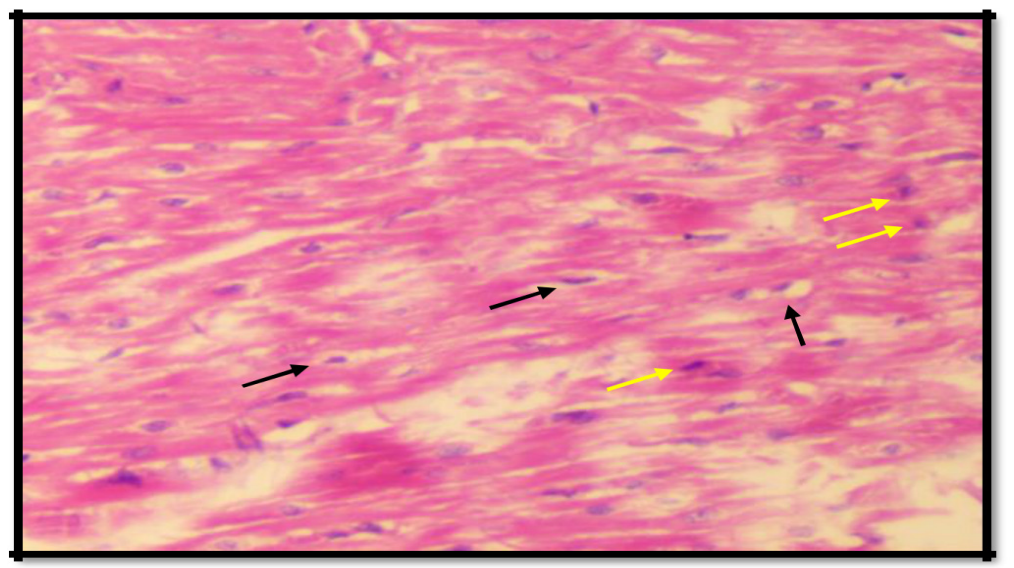

Fig. 3. Transverse histological section of myocardial muscle showed vacuolar degeneration in myocardial cells(black arrows)with pyknotic nuclei in some necrotic myocytes which revealed to coagulative necrosis (yellow arrows) H\&E stain. 10X.

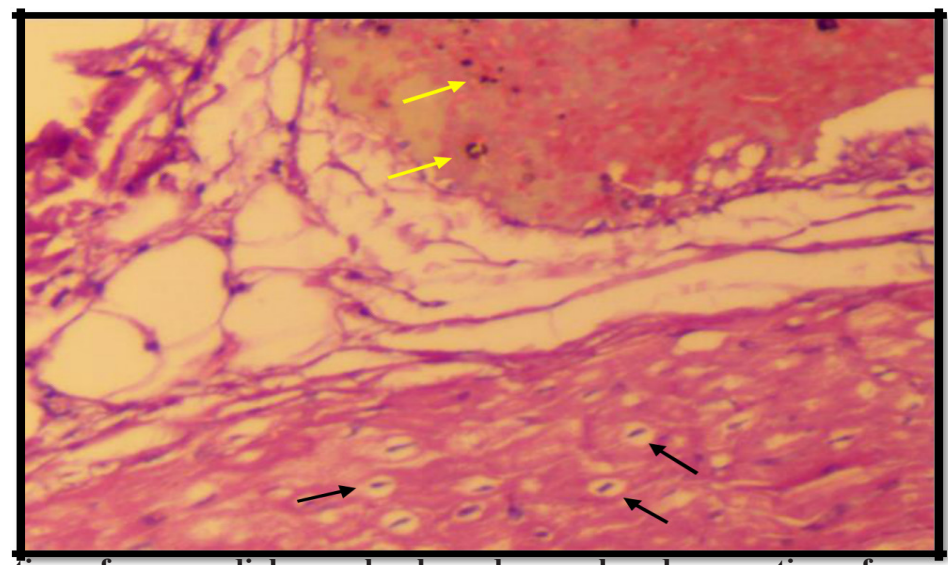

Fig. 4.Transverse section of myocardial muscle showed vacuolar degeneration of myocytes( black arrow) thrombotic mass with slight infiltration of inflammatory cells in addition of discontinuation of cardiac muscle fiber .H\&E stain. 10X.

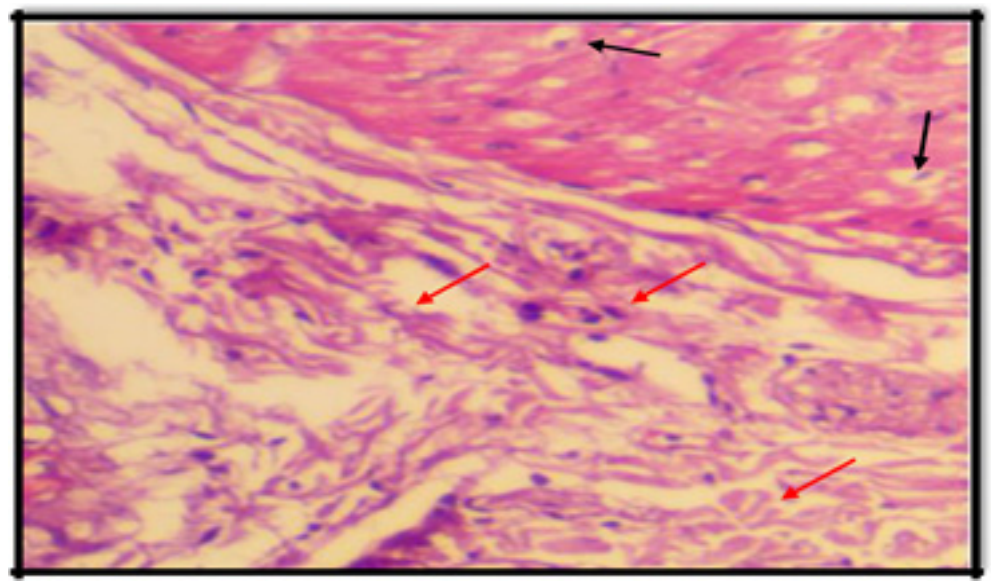

Fig. 5. Showed vacuolar change in the myocytes ( black arrow) in addition to edema between muscle fiber (black arrow) in addition to deposition of fibrous tissues accompanied by infiltration of inflammatory cells revealed to interstitial fibrinous myocarditis (red arrow) . H\&E stain. 10X. 


\section{Discussion}

Selenium and Vitamin E have integral and maybe have also a distinct role as a preventive of oxidative stress element and are an important ingredient for the animals. Thereby, it represents several antioxidants and other minerals which have an essential function in the immune responses, However, it might affect animal health and the growth of the muscle and its functions in calves of different ages [10].

It was shown that Vitamin $\mathrm{E}$ is created by the plants, However, animals can store but not synthesized. Grass usually have high and enough quantities of $\alpha$-tocopherol, while, lush types of spring herbs contain a lot of polyunsaturated fatty acids. Therefore, when it is consumed by the grazing animals, these polyunsaturated fatty acids will rapidly oxidize. On the other hand, the vitamins contained in the food materials will always be affected by the storage methods[11].

Which should be referred to, in this study that the clinical cases of diseased calves were coming for the purpose of treatment or diagnosis from different farms at Basrah, Iraq. Moreover, the percentage values of vitamin $\mathrm{E}$ or selenium was not measured in rations of sick animals, as the animals switched from indoor feeding to external grazing in an unexpected way.

Diagnosis of the vitamin E deficiency in acute cases of myopathy in calves should be straight and modest, and also should depend on the history of modern turnout or more exercise, also with a high intake of lush green grasses or could depend on a farm history of low vitamin $\mathrm{E}$ and/or selenium. However, the white streaking in the muscles indicated on the carcass muscles will reflect the muscle damage [12].

The nutritional muscular dystrophy associated with vitamin $\mathrm{E}$ and/ or selenium deficiencies was stated with different disease troubles which described in different animals globally, However, it also described to occur in calves feeding milk, in young cattle at the early grazing period, and in pregnant animals at the last stage of pregnancy and post-calving cows, The important role in the evolvement of the disease refers to the high consumption of unsaturated fatty acids[13].

Further reasons which could engage in the permanence and persistence of muscular dystrophy are the excessive muscular activates and un-favorable climate which rises the demand for energy sources. All the mentioned causes might stimulate the manifestations of clinical acute and/or sub-acute muscular dystrophy[14].

Diseased animals of the current study show different clinical manifestations which were also mentioned by some authors $[4,15]$.

The acute type of muscular damage, which progress suddenly could be the cause of the sudden death syndrome and the prolonged recumbence were seen in diseased adult calves which might reflect the harm oxidative damage affected the skeletal and cardiac muscles, Moreover, the irregularity of the heart and respiratory rate has a strong and clear link $[1,16]$.

Huang et al. [17] was also added that, in acute cases of nutritional muscular dystrophy, motor disturbances, like an unsteady gait with stiffness especially in the neck, lumbar region, muscles of the forelimb with muscle tremors, excessive sweating, and sudden collapse are encountered.

Macrocytic normochromic anemia was indicated in diseased adult calves of the current study. (McDowell, 2000) [18] was referred to the increase of the osmotic fragility of erythrocytes and ineffective erythropoiesis and enhanced the premature lysis in some instances of vitamin E deficiency, also, it was well assumed that Vitamin E might cause hemolytic anemia which calls ( free radical-induced hemolytic anemia's), Since it is responsible for the protection of erythrocyte cell membranes from the oxidative damage, Therefore, the deficiency will enhance the blood cell fragility which indicated in the current study [13].

Scientific sources emphasized that a confirmed relationship has been detected between the vitamin E deficiency and the activity of clotting factor indices, It was proved that vitamin $\mathrm{E}$ is an inhibitor agent for the thrombocytes aggregation in humans and pigs and maybe in other animals via depression of the peroxidation process of arachidonic acid, which is needed for the creation of the prostaglandins involved in platelets clumping $[5,19]$. Moreover, Galli et al. and Bourne et al. $[3,12]$ added, that, Vitamin E diseased animals will show an increase of plasma thromboxane that is relieved by vitamin E supplement, Thereby, it was postulated that the deficiency of vitamin $\mathrm{E}$ might enhance and maintain the clot formation and promote the Dissemination of intravascular coagulation mechanisms. 
In the current study a significant decrease in vit. $\mathrm{E}$ and selenium values have been recorded. It was proven that, though vitamin $\mathrm{E}$ is the main lipid-soluble antioxidant in the body, However, not all its specifications and criteria can be detected to this action. As an antioxidant, vitamin $\mathrm{E}$ acts in cell membranes to prevents the spreading of free radical interactions and reactions, although it has been also shown to have pro-oxidant activities [16].

In addition, non-radical oxidation products will originate via the reaction between alphatocopheryl radical and other free radicals, which are combined with glucuronic acid and excreted via both the bile or the urine. Besides, vitamin $\mathrm{E}$ is transported in plasma lipoproteins, and after the intestinal absorption of vitamin $\mathrm{E}$ it will be packaged into chylomicrons, which along the lymphatic pathway will be secreted into the systemic circulation [17]. On the other hand, some searchers were also added that the accumulation of the toxic peroxide activity could terminate with cell membrane harm followed by tissue damage resulting in myopathy. This peroxidative damage action is associated with enhanced liberation of the lysosomal enzymes, as the activity of which can rise to several times at the beginning of noticing clinical symptoms $[15,17]$.

Enhancing of tissue oxidation because of Vit.E and/ or selenium deficiency were un- control of muscles, nerves, and also senses, including a disturbance of contraction of muscles, allowing motions, heartbeats, rumen, and pulmonary functions, which are all influenced by deficiency status. Moreover, Food conversion rate, growth, and reproduction are also affected[20].

Results of biochemical analysis of the current study show a significant increase in the values of $\mathrm{CK}$, and AST compared with the healthy adult buffalo calves. It had been documented that the most related factor in the laboratory diagnosis of muscular damage is creatine kinase enzyme. It's the most specific and sensitive index of muscular damage. The enzyme is highly particular and specific for both skeletal and cardiac muscles and is liberated directly into the blood after unusual exercise and muscular degenerations. However, although, aspartate aminotransferase is an index for muscle damage, However, it had minimum specificity because it released also from other damaged hepatocytes. In general, the increased levels of both enzymes in diseased animals have just been turned out and exposed to un-common exercise $[5,15]$.
Myocardial damage leading to the increased circulating serum of troponin I. concentrations have been reported in different clinical diseases such as pericarditis, endocarditis, the cardiac form of foot-and-mouth disease, and even non-cardiac intra-thoracic disorders. Moreover, a positive correlation between the magnitude of the troponin level concentration and the severity of histological evidence of myocardial injury was also reported[21].

In general, Analysis of cardiac troponin is considered as the approved scale in the clinical and laboratory diagnosis of myocardial injury in both animals and humans because of its high sensitivity and specificity. The troponin-specific function is to control the calcium-mediated interaction between actin and myosin, for permitting contraction at the sarcomere level. Furthermore, it was shown that its concentration could remain high in blood circulation for at least 1-2 weeks, thereby, a high range will be obtained for the laboratory confirmation of cardiac muscle harm [22].

Results of post mortem analysis show enlargement of the heart which appears sphericallike shape, moreover, white-colored lesions of degeneration, which appears more evident, particularly under the endocardium was also indicated.

Constable et al. [15] and Allison \& Laven[23] mentioned that the gross appearance of the lesions found in the muscles was constant, However, these lesions are varied extremely in various animals. The lesions may contain localized areas of whitish or grayish coloration that reflected the degeneration and necrosis. Furthermore, it was recognized that in cases associated with cardiac effects, a white color region of degenerations will notice, especially under the endocardium area at the left part of the calves ventricle and of both left and right ventricles in lambs. However, these lesions might spare to include the papillary muscles and the inter-ventricular septum and have a gritty character consistent with mineralization. The presence of congested and edematous lungs was also a common finding. On the other hand, the histopathological picture indicated noninflammatory muscle lesions which are seen in all animal species represented with hyaline degeneration is followed by coagulation necrosis and variable degrees of mineralization which are also indicated in the current study [16,19].

Egypt. J. Vet. Sci. Vol. 52, No. 3 (2021) 


\section{Conclusions}

It has been concluded that acute dystrophy of cardiac muscles arising from deficiency of vitamin E/ or selenium has an adverse harmful acute effect on affected adult calves mostly terminated with sudden death, Therefore, feeding of animal must be noted continuously which should be always provided with balanced diets to avoid the occurrence of nutritional deficiency diseases and the occurrence of economic losses that may sometimes be large.

\section{Acknowledgments}

Thanks and appreciation submitted to the College of Veterinary Medicine, University of Basrah, Iraq, and the Department of Internal and Preventive Medicine for their cooperation.

\section{Competing interest statement}

The authors state that there is no competing interest in this research

\section{Funding statement}

The College of Veterinary Medicine / University of Basrah, Iraq is the financial support for this research

\section{References}

1-Mène-Saffrané, L. and Pellaud, S. Current strategies for vitamin E biofortification of crops. Curr. Opin. Biotechnol., 44, 189-197 (2017).

2-Mene-saffrane, L. Vitamin E. biosynthesis and its regulation in plants Antioxidant, 7(1),pages 1-17(2018). doi: 10.3390/antiox7010002

3-Galli, F., Azzi, A., Birringer, M., Cook-Mills, J.M., Eggersdorfer, M., Frank, J., Cruciani, G., Lorkowski, S. and Katar Özer, N. Vitamin E: Emerging aspects and new directions. Free Radic. Biol. Med., 102, 16-36(2017).

4- Pavlata, L ., Pechova, A . and Illek, J . Muscular Dystrophy in Dairy Cows Following a Change in Housing Technology. Acta. Veterinaria Brno., 70(3),269-275(2001).

5- Sharma, M.C., Raju, S., Joshi, C., Kaur, H. and Varshney, V.P. Studies on serum micro-mineral, hormone and vitamin profile and its effect on production and therapeutic management of buffaloes in Haryana state of India. Asian Austral. J. Anim., 16(4), 519-528(2003).
6- Khan, H. M., Mohanty, T. K., Bhakat, M., Gupta, A.K. and Mondal, G. Effect of vitamin e and mineral supplementation during peri-partum period on bcs, body weight and calf performance in murrah buffaloes. Buffalo Bull., 34(1), 79-85(2015).

7- Dayyal, D. "Bleeding Time (BT) and Clotting Time (CT)". BioScience., 10-26. (2016). ISSN 25215760. Retrieved 2017-10-26.

8- Weiss, D.J and Wardrop, K.J. Schalm's Veterinary Hematology, $6^{\text {th }}$ Ed, Ames, Wiley-182 Blackwell. (2010).

9- Leech,N., Barrett,K. and Morgan, G.A., SPSS for intermediate statistics :Use and interpretation. Routledge (2013).

10- Hefnawy, A.E.G. and Tórtora-Pérez, J.L. The importance of selenium and the effects of its deficiency in animal health. Small Rumin. Res., 89,185-192(2010).

11- Van Metre, D.C. and Callan, R.J. Selenium and vitamin E. Vet. Clin. North Am. Food Anim. Prac., 17(2), 373-402, vii-viii. (2001).

12- Bourne, N., Wathes, D., McGowan, M. and Lavern, R. Physiological Responses in Dairy Cattle Supplemented with Vitamin E above NRC Requirements. Cattle Prac., 11(4), 367-372. (2003).

13- Jilani, T. and Iqbal, M.P. Vitamin E deficiency in South Asian population and the therapeutic use of alpha-tocopherol (Vitamin E) for correction of anemia. Pak. J. Med. Sci., 34 (6), 1571-1575 (2018)

14- Descalzo, A. M., Insani, E. M., Biolatto, A., Sancho, A. M., García, P. T., Pensel, N. A. and Josifovich, J. A. Influence of pasture or grain-based diets supplemented with vitamin E on antioxidant/ oxidative balance of Argentine beef. Meat Sci., 70(1), 35-44(2005).

15- Constable, P.D, Hinchcliff, K.W, Done, S.H. and Grunberg, W. Veterinary Medicine. A textbook of the diseases of cattle, sheep, goats and horses $\left(11^{\text {th }}\right.$ ed.), WB Saunders (2017).

16-Herrera, E. and Barbas, C. Vitamin E: action, metabolism and perspectives. J. Physiol. Biochem., 57(2), 43-56(2001). 
17- Huang, J., Weinstein, S.J ., Yu, K ., Männisto, S. and Albanes, D. Relationship Between Serum Alpha-Tocopherol and Overall and Cause-Specific Mortality. Circ. Res., 125, 29-40 (2019).

18- McDowell, L.R. Vitamins in Animal and Human Nutrition, 2nd ed., Iowa State University Press, Ames, IA. (2000).

19- Žust, J., Hrovatin, B. and Šimundić, B. Assessment of selenium and vitamin $\mathrm{E}$ deficiencies in dairy herds and clinical disease in calves. Vet. Rec., 139, 391-394(1996).

20- Sivertsen, T., Overnes, G., Osterås, O., Nymoen, U. and Lunder, T. Plasma vitamin E and blood selenium concentrations in Norwegian dairy cows: regional differences and relations to feeding and health. Acta Vet. Scandinav., 46(4), 177-191(2005).
21- Varga, A., Angelos, J, Graham,A. and Chigerwe, T.W.M. Preliminary Investigation of Cardiac Troponin I Concentration in Cows with Common Production Diseases. J. Vet. Intern. Med., 27, 1613-1621(2013).

22-Vishal, V., Undhad, D.T., Fefar, B.M., Gupta, J.H., Ghodasara, D.J., Josh, B.P. and Prajapati, Ka. S. Cardiac troponin: an emerging cardiac biomarker in animal health. Vet. World, 5(8), 508-511(2012).

23- Allison, R.D. and Laven, R.A. Effect of vitamin E supplementation on the health and fertility of dairy cows: a review. Vet. Rec., 147(25), 703-708 (2000).

\title{
دراسة سريرية و دمومية و كيموحيوية وامراضية للحثل العضلي التغذوي الحاد لعجول الجاموس البالغة في البصرة ، الكراقة

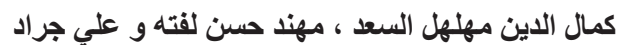 \\ كلية الطب البيطري ـ فرع الطب الباطني و الوقائي ـ جامعة البصرة ـ العر اق.
}

\begin{abstract}
درس الحثل العضلي التغذوي الحاد على اربع وستون حيو اناً من عجول الجاموس البالغة المشتبه بإصابتها

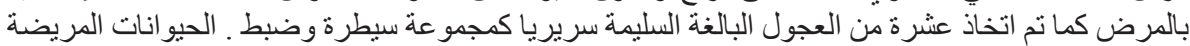

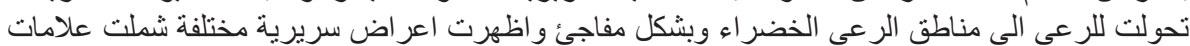

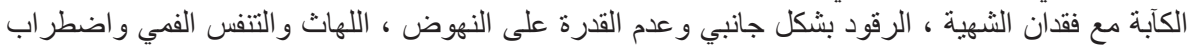

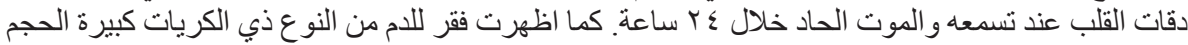

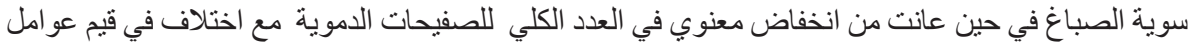

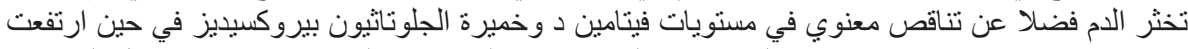

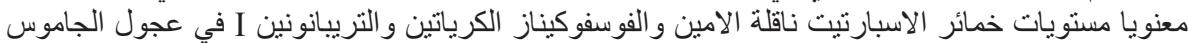

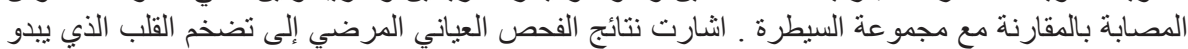

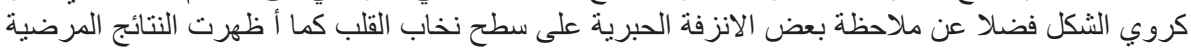

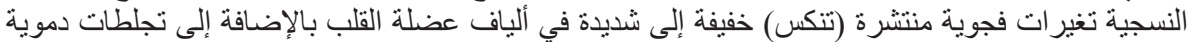

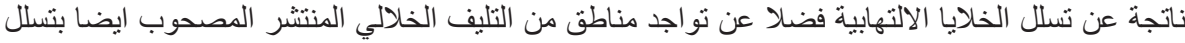
الخلايا الالتهابية في عضلة القلب التلبا.

استتتج من هذه الدراسة ، أن الخثل الحاد لعضلات القلب له تأثير ضار على العجول المريضة التي تنتهي في

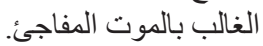

